\title{
Effect of bio-agents on pathogenic fungi associated with roots of some deciduous fruit transplants and growth parameters in New Valley Governorate, Egypt
}

\author{
Magd El-Morsi Awad El-Morsi, Montaser Fawzy Abdel-Monaim*
}

Plant Pathology Research Institute, Agricultural Research Center, 72514, Giza, Egypt

Received: November 5, 2014

Accepted: March 17, 2015

\begin{abstract}
Root rot and wilt disease complex was detected in several fig (Ficus carica L.), grapevine (Vitis vinifera L.), and pomegranate (Punica granatum L.) transplants in nurseries and new orchards of the El-Kharga, Baris, Balate, El-Dakhla, and El-Farafrah districts, of the New Valley governorate, Egypt. The percentage of root rot/wilt incidence and severity on fig, grapevine, and pomegranate transplants in the surveyed districts differed. The average percentages of root rot/wilt incidence and severity, in the surveyed districts, were $41.26,31.42 \%$ in fig, 38.2, 29.5\% in grapevine, and 32.1, 23.7\% in pomegranate transplants, respectively. The most frequently isolated fungi from rotted roots of fig, grapevine, and pomegranate transplants were Fusarium oxysporum, Rhizoctonia solani, and Macrophomena phaseolina. In pathogenicity tests, all the tested fungi were pathogenic to fig, grapevine, and pomegranate transplants. Under laboratory conditions, all of the following tested bio-agents: Azotobacter sp., Bacillus cereus, B. megaterium, and B. subtilis, were able to inhibit growth of the causal pathogens to different degrees. The effect of these bio-agents individually and/or mixed, when used as a soil drench treatment, were varied in reducing the incidence and severity of root rot/wilt diseases in fig, grapevine, and pomegranate transplants under greenhouse conditions. The mixed bio-agents gave the highest protection against root rot/wilt diseases compared with the individually used of bio-agents. All treatments significantly increased plant height, number of leaves/transplant, leaf area, fresh and dry weight/transplant compared with the control treatment.
\end{abstract}

Key words: bioagents, fig, grapevine, growth parameters, pomegranate, root rot/wilt diseases, transplants

\section{Introduction}

Fig (Ficus carica L.), grapevine (Vitis vinifera L.), and pomegranate (Punica granatum L.) are important economic fruit crops throughout the world as well as in Egypt. Fig, grapevine, and pomegranate transplants are subject to attack by several soil-borne pathogens. The pathogens cause severe deterioration to the transplants in nurseries and new orchards. Root rot and wilt diseases of fig, grapevine, and pomegranate transplants are primarily caused by several pathogens including, Fusarium oxysporum, F. solani, Rhizoctonia solani, and Macrophomina phaseolina, and other fungi (Walker 1992; Krol 2006; Ziedan and El-Mohamedy 2008; Kishore and Bhardwaj 2011; Ziedan et al. 2011). These pathogens are capable of surviving in the soil in the absence of their host plants, and might become destructive under favorable conditions.

The governorate of New Valley, Egypt has high temperatures and low relative humidity. In these conditions, the root rot and wilt of transplants of young fig, grapevine, and pomegranate trees have been observed in the early stages of plant development in nurseries or after being transplanted to new orchards.

Successful control of such diseases has been obtained by using a wide array of fungicides. The extensive appli- cation of chemical fungicides is harmful to humans, living organisms, and the environment. A promising strategy for the replacement of chemical pesticides has been the implementation of biological control. In recent years, biological control has been suggested as a potentially attractive alternative disease management and disease reduction method for use with many crops. The bio-agents Azotobacter sp., Bacillus cereus, B. megaterium, and B. subtilis produce biologically active compounds (antibiotics and toxic substances) that have antifungal activity. Bioactive compounds, including plant growth regulators, protect and are effective against a broad spectrum of plant pathogens. These compounds can be applied successfully in many areas of plant production as a plant growth stimulant or soil conditioner for enhancing natural resistance against plant diseases, stimulation of plant growth through increased cell division, as well as for optimizing the uptake of nutrients and water. Moreover, such treatments stimulated growth of the useful soil microorganisms, as mentioned by Kloepper et al. (2004), Dakhly et al. (2007), El-Mohamedy and Ahmad (2009), Baset et al. (2010), Osman and Abd El-Rhman (2010), Islam et al. (2012), Abdel-Monaim et al. (2012), Shobha and Kumudin (2012), and Abdel-Monaim (2013). 
The present work was planned to assess a root rot/ wilt survey. The present work was also done to evaluate the effect of certain bio-agents as single treatments and/ or in combination for controlling the diseases. The effects of bio-agents on growth parameters of fig, grapevine, and pomegranate transplants in the governorate of New Valley were evaluated.

\section{Materials and Methods}

\section{Diseases survey}

A survey of root rot and wilt diseases was carried out in nurseries and new orchards at the El-Kharga, Baris, Balate, El-Dakhla, and El-Farafrah districts in the governorate of New Valley. The percentages of diseased fig, grapevine, and pomegranate transplants, showing symptoms of root rot and/or wilt diseases, were recorded. Disease severity was assessed on transplants which exhibited symptoms typical of root rot and/or wilt diseases. Foliar symptoms, including dull, internally rolled or necrotic leaves, defoliated and dead twigs, were evaluated on a scale of $0-4$ based on the percentage of the affected foliage. The scale was: 0 - healthy transplants, 1 - from 0 to $25 \%$ (milled symptoms), 2 - from 26 to $50 \%$ (intermediate symptoms), 3 - from 51 to $75 \%$ (severe symptoms), 4 - more than $76 \%$ diseased foliage (transplants nearly dead to dead).

Disease severity (DS) described by Liu et al. (1995) was adapted and calculated as follows:

$$
D S=\sum d /\left(d_{\max } \times n\right) \times 100,
$$

where: $d$ - the disease rating of each transplant, $d_{\max }$ - the maximum disease rating, and $n-$ is the total number of transplants/sample examined in each replicate.

\section{Isolation and identification of the causal fungi}

Diseased roots of fig, grapevine, and pomegranate transplants showing yellowing or wilt symptoms were collected and taken for isolation. The root samples were thoroughly washed under running tap water then cut into small pieces $(1 \mathrm{~cm})$. These pieces were surface sterilized by dipping them in $0.1 \%$ mercuric chloride solution for 2 min and then washing them several times with sterile distilled water. The surface sterilized pieces were blotted dry on sterilized filter paper, and transferred individually to Petri dishes. Each dish contained $20 \mathrm{ml}$ Potato Dextrose Agar (PDA) medium. Incubation was done at $25^{\circ} \mathrm{C}$ for 5-7 days and then an inspection for fungal growth was done. The developed fungal colonies were purified using hyphal tip or single spore techniques. The purified fungi were identified according to the fungal morphological and microscopical characteristics described by Barnett and Hunter (1986) and Sneh et al. (1991) and confirmed by the Botany Department, Faculty of Science, Assiut University. The obtained culture isolates were maintained on PDA slants and kept in refrigerator at $5^{\circ} \mathrm{C}$ for further study.

\section{Pathogenicity tests}

The pathogenic capability of the isolated fungi was carried out under greenhouse conditions at the El-Kharga Agricultural Research Station. Plastic pots (30 cm in diameter) were sterilized by dipping in a $5 \%$ formalin solution for $15 \mathrm{~min}$. The soil was sterilized with formalin solution (5\%), then covered with a polyethylene sheet for 7 days to retain the gas, and left to dry for 2 weeks until all traces of formaldehyde disappeared. The sterilized pots were filled with sterilized soil $\left(5 \mathrm{~kg} \cdot \mathrm{pot}^{-1}\right)$. The tested fungi were grown on autoclaved barley grain medium in $500 \mathrm{ml}$ glasses. Inoculation was done with discs $(5 \mathrm{~mm}$ in diameter) taken from 7 day-old cultures of each tested fungal isolate, then incubated at $27 \pm 1^{\circ} \mathrm{C}$ for 15 days. The sterilized soil was individually infested with the tested fungi at the rate of $5 \%$ of the soil weight. The pots were irrigated regularly three times a week before planting to ensure even distribution of the inoculated fungus in the soil. Four fig, grapevine, and pomegranate transplants (ten-months old) were cultivated in each pot and six pots were used as replicates. Six pots containing non-infested soil were cultivated at the same transplanting rate as those used as the control. The percentages of incidence and severity were recorded three months after being planted in pots. Re-isolation was carried out from the infected transplants showing disease symptoms. The isolated fungus was compared with the original culture used.

\section{Source of the bio-agents and inoculum preparation}

The four bio-agents obtained from Plant Pathology Department of the New Valley Agricultural Research Station and used in this study were Azotobacter sp. (isolate AZM1), Bacillus cereus (isolate BCM8), B. megaterium (isolate BMM5), B. subtilis (isolate BSM1). These bio-agents were isolated by Dr Montaser Fawzy Abdel-Monaim, and were previously tested against several soil borne pathogens (Abdel-Monaim 2010; Abdel-Monaim et al. 2012; AbdelMonaim 2013). The inoculum was produced as described by Landa et al. (2004). Bacterial concentration in suspension was adjusted to approximately $5 \times 10^{8}$ cells $\cdot \mathrm{ml}^{-1}$ by measuring the absorbance at $600 \mathrm{~nm}$ in a spectrophotometer and using standard curves for each bacterial isolate.

\section{Effect of bio-agents on the growth of the tested pathogenic fungi in vitro}

The tested isolates of antagonistic bio-agents were streaked on one side of the PDA medium in plates. Incubation was done for $24 \mathrm{~h}$ at $25 \pm 1^{\circ} \mathrm{C}$. Then, discs $(7 \mathrm{~mm}$ in diameter) of pathogenic fungi were placed on the opposite side. Four replicates were used for the treatment. Inoculated plates with pathogenic fungi only, were used as the control. After 7 days of incubation, the linear growth of pathogenic fungi in all treatments was recorded. The decrease of percentage that occurred in the linear growth of the pathogenic fungi was determined at the end of the experiment using the following formula suggested by Fokemma (1973): 
Reduction in linear growth $=[(R 1-R 2) / R 1] \times 100$,

where: $R 1$ - the radius of normal growth in the control plates; $R 2$ - the radius of inhibited growth.

\section{Effect of bio-agents on root rot and wilt diseases in vivo}

The bio-agents (Azotobacter sp., B. cereus, B. megaterium, B. subtilis, a mix of them, and one fungicide (Rizolex-T/ Tolclofosm methyl + Thiram $/ 50 \% \mathrm{WP} / 3 \mathrm{gm} \cdot \mathrm{l}^{-1}$ ) were evaluated to control root rot and wilt diseases on fig, grapevine, and pomegranate transplants. This experiment was carried out on healthy looking fig (cv. Albersomy), grapevine (cv. Flame seedless), and pomegranate (cv. Manfalouti) under pot experiments.

Four fig, grapevine, and pomegranate transplants (ten-months old) were cultivated in each pot on 15 January 2014. Six pots were used replicates. Six pots containing non-infested soil were cultivated at the same transplanting rate and used as the control.

Six pots of each treatment were used as replicates containing sterilized soil previously infested with inoculum of each fungus. The pots were drenched with each of the tested bio-agents ( $250 \mathrm{ml}$ per pot), and 7 days later the soil was infested. Four fig, grapevine, and pomegranate transplants (ten-months old) were cultivated in each pot on 1st February, 2014. After three months, the disease severity (DS) and efficacy values were calculated according to the following formula:

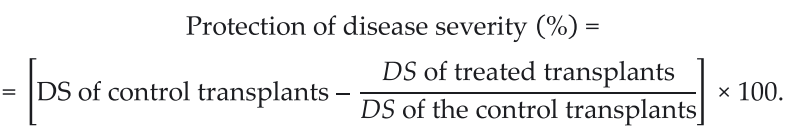

The vegetative growth parameters i.e. plant height $(\mathrm{cm})$, number of leaves per plant ${ }^{-1}$, leaf area $\left(\mathrm{cm}^{2}\right)$ according to Ahmed and Morsy (1999) as well as fresh and dry weights $\left(\mathrm{gm} \cdot\right.$ plant $\left.^{-1}\right)$ were recorded at the end of experiment.

\section{Statistical analysis}

All experiments were performed twice. Analyses of variance were done using MSTAT-C program version 2.10
(1991). The least significant difference (LSD) was calculated at $\mathrm{p} \leq 0.05$ according to Gomez and Gomez (1984).

\section{Results}

\section{Survey of root rot and wilt diseases}

Typical symptoms of root rot and wilt on fig, grapevine, and pomegranate transplants were observed in five examined districts of the governorate of New Valley. Data in table 1 indicate that disease incidence and the severity of root rot and wilt disease complex, differed on fig, grapevine, and pomegranate transplants in different inspected locations of the governorate of New Valley. Disease incidence and disease severity of fig transplants ranged from 25.3 to $56.3 \%$ and 16.3 to $43.7 \%$, respectively. While, disease incidence and disease severity of grapevine transplants ranged from 30.6 to $43.7 \%$ and 21.6 to $37.1 \%$, respectively. Also, disease incidence and disease severity of pomegranate transplants ranged from 26.8 to $40.2 \%$ and 19.2 to $30.4 \%$, respectively. Generally, the disease incidence and disease severity differed at the five inspected locations. The highest disease incidence and disease severity in the tested fruit crops were recorded in the El-Dakhla district and the lowest diseases incidence and disease severity were recorded in the El-Farafrah district. Then again, disease incidence and severity differed for different fruit crops. The highest means of disease incidence and disease severity were recorded for grapevine transplants ( 38.2 and $29.5 \%$, respectively) followed by fig transplants (41.26 and $31.42 \%$ ), while pomegranate transplants revealed the lowest means (32.1 and 23.7\%).

\section{Isolation, identification, and pathogenicity tests}

The obtained results from isolation trials shown that F. oxysporum, M. phaseolina, and R. solani were the main causal pathogens found on the studied fruit crops growing in the governorate of New Valley. These were the fruit crops which showed typical symptoms of root rot and wilt diseases.

Data presented in table 2 show that all the tested fungi were pathogenic to fig, grapevine, and pomegranate transplants. The pathogenic fungi isolates exhibited dif-

Table 1. Occurrence of root rot/wilt disease complex of fig, grapevine, and pomegranate transplants in different nurseries and new orchards in the governorate of New Valley

\begin{tabular}{|c|c|c|c|c|c|c|}
\hline \multirow{2}{*}{ Locations } & \multicolumn{2}{|c|}{ Fig } & \multicolumn{2}{|c|}{ Grapevine } & \multicolumn{2}{|c|}{ Pomegranate } \\
\hline & $D I^{a}$ & $D S^{\mathrm{b}}$ & $D I$ & $D S$ & $D I$ & $D S$ \\
\hline El-Kharga & 43.7 & 32.6 & 39.1 & 29.3 & 30.6 & 21.6 \\
\hline Baris & 35.4 & 27.7 & 37.5 & 26.0 & 27.2 & 19.2 \\
\hline Balat & 45.6 & 36.8 & 40.3 & 33.3 & 35.7 & 27.0 \\
\hline El-Dakhla & 56.3 & 43.7 & 43.7 & 37.1 & 40.2 & 30.4 \\
\hline El-Farafrah & 25.3 & 16.3 & 30.6 & 21.6 & 26.8 & 20.4 \\
\hline The mean & 41.26 & 31.42 & 38.2 & 29.5 & 32.1 & 23.7 \\
\hline
\end{tabular}

${ }^{a} D I$ - disease incidence; ${ }^{b} D S$ - disease severity 
Table 2. Pathogenicity tests of fungi isolated from diseased samples collected from fig, grapevine, and pomegranate transplants in greenhouses

\begin{tabular}{|c|c|c|}
\hline Fungi & $\%$ Disease incidence & $\%$ Disease severity \\
\hline \multicolumn{3}{|c|}{ Fig } \\
\hline Fusarium oxysporum & 88.89 & 82.59 \\
\hline Macrophomina phaseolina & 100.00 & 86.28 \\
\hline Rhizoctonia solani & 88.89 & 76.29 \\
\hline The mean & 92.59 & 81.72 \\
\hline \multicolumn{3}{|c|}{ Grapevine } \\
\hline Fusarium oxysporum & 100.00 & 85.69 \\
\hline Macrophomina phaseolina & 100.00 & 100.00 \\
\hline Rhizoctonia solani & 100.00 & 92.58 \\
\hline The mean & 100.00 & 89.47 \\
\hline \multicolumn{3}{|c|}{ Pomegranate } \\
\hline Fusarium oxysporum & 88.89 & 76.36 \\
\hline Macrophomina phaseolina & 88.89 & 80.25 \\
\hline Rhizoctonia solani & 100.00 & 82.47 \\
\hline The mean & 92.59 & 79.69 \\
\hline
\end{tabular}

ferent degrees of pathogenic capabilities. However, the transplants inoculated with the tested fungi appeared as crown and root rots characterized by light to dark colours and foliar wilting symptoms. In the case of the fig transplants, M. phaseolina caused the highest root rot incidence $(100 \%)$, and severity $(86.28 \%)$. While in the case of grapevine, all tested fungi caused $100 \%$ root rot/wilt incidence, and caused $85.69,100,92.58 \%$ root rot/wilt severity. On the other hand, pomegranate transplants were affected with $R$. solani rather than F. oxysporium and M. phaseolina. Pomegranate transplants affected with $R$. solani showed $100 \%$ root rot incidence and $82.47 \%$ root rot severity.

\section{Evaluation of the antagonistic activities of bio-agents in vitro}

The bio-agents (Azotobacter sp., B. cereus, B. megaterium, and $B$. subtilis) were evaluated for their antagonistic effect against $F$. oxysporum, M. phaseolina, and $R$. solani in Petri dishes containing PDA medium. The data in table 3 show that all the tested bio-agents succeeded in reducing the radial growth of the tested pathogenic fungi. Bacillus subtilis recorded the highest inhibition of the tested pathogenic fungi followed by B. megaterium and B. cereus. While, Azotobacter sp. recorded the lowest.

Efficacy of some bio-agents and fungicide root rot/wilt severity and vegetative growth parameter in vivo

On root rot/wilt severity

Results in tables 4 to 6 shows that all the tested bio-agents, and Rizolex-T (the positive control) reduced the severity of root rot/wilt disease on fig, grapevine, and pomegranate transplants. This refers to the severity of root rot/wilt disease caused by F. oxysporum, M. phaseolina, and R. solani when applied individually or mixed as a soil drench in pots. Efficiency of the tested bio-agents for controlling these diseases was varied. The bio-agent mixtures significantly reduced root rot/wilt disease severity when these bio-agents were used individually. Also, the bio-agent mixtures were the best fungicides for controlling root rot/ wilt diseases. The bio-agent mixtures also recorded the highest protection against $R$. solani infection followed by M. phesolina and F. oxysporum in the case of fig transplants, and M. phasolina followed by F. oxysporum and $R$. solani in the case of grapevine and pomegranate.

\section{Vegetative growth parameter}

Effects of bio-agent strains, either individually and/or mixed, on some growth parameters of fig, grapevine, and pomegranate transplants under artificial infection with F. oxysporum, M. phaseolina, R. solani in pots, was studied. The obtained data in tables 4 to 6 reveal low values of growth parameters, plant height $(\mathrm{cm})$, number of leaves per plant, leaf area $\left(\mathrm{cm}^{2}\right)$, and fresh and dry weights $\left(\mathrm{gm} \cdot\right.$ transplant $\left.^{-1}\right)$ in the control treatment when compared with the other treatments. All tested growth parameters of fig (Table 4), grapevine (Table 5), and pomegranate transplants (Table 6) were significantly increased with the mixed inoculation of bio-agent strains compared with the individual bio-agent inoculations. Also, the mixed bio-agents significantly increased growth parameters in all tested fruit crops, more than when Rizolex-T (the positive control) was used. 


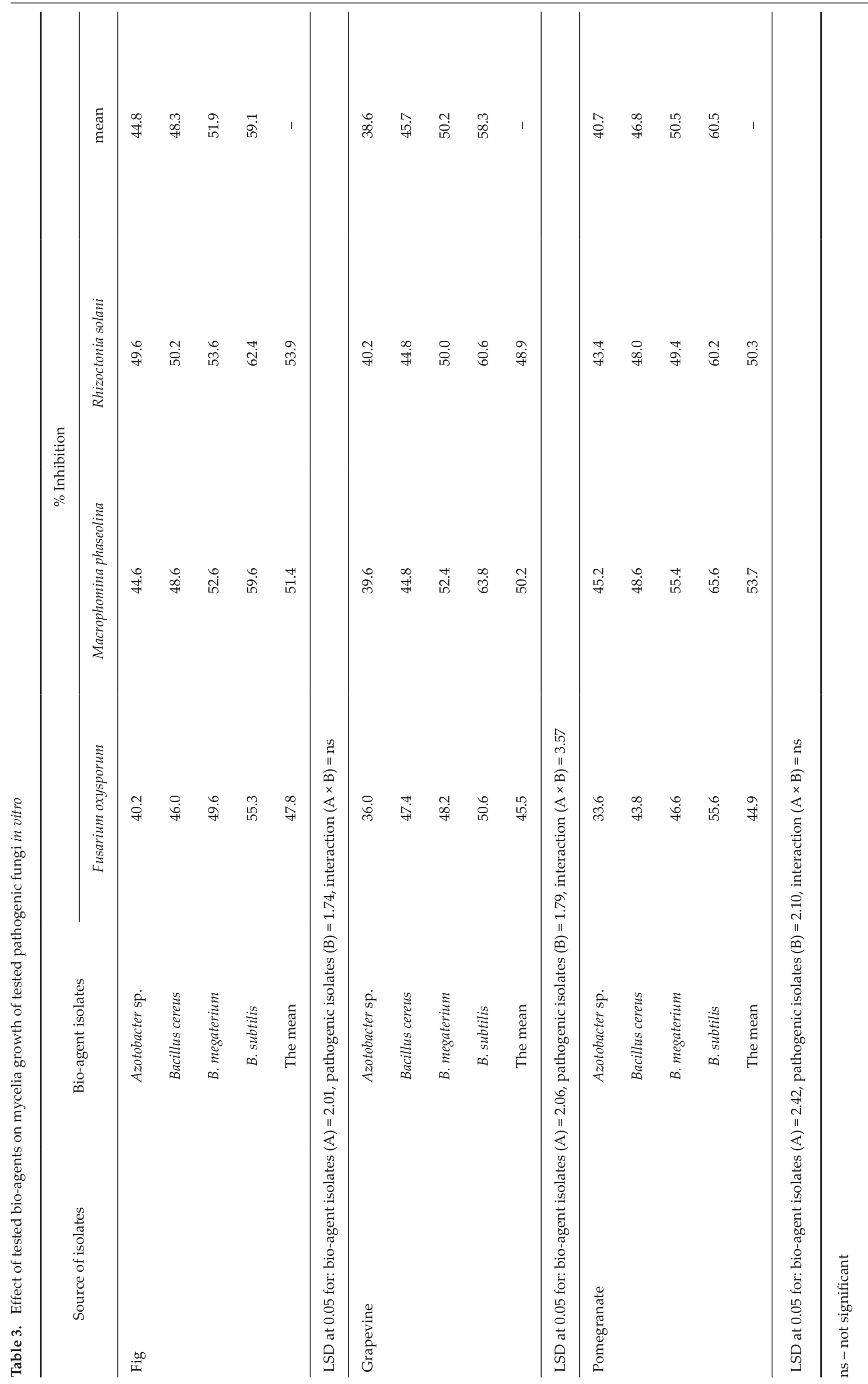




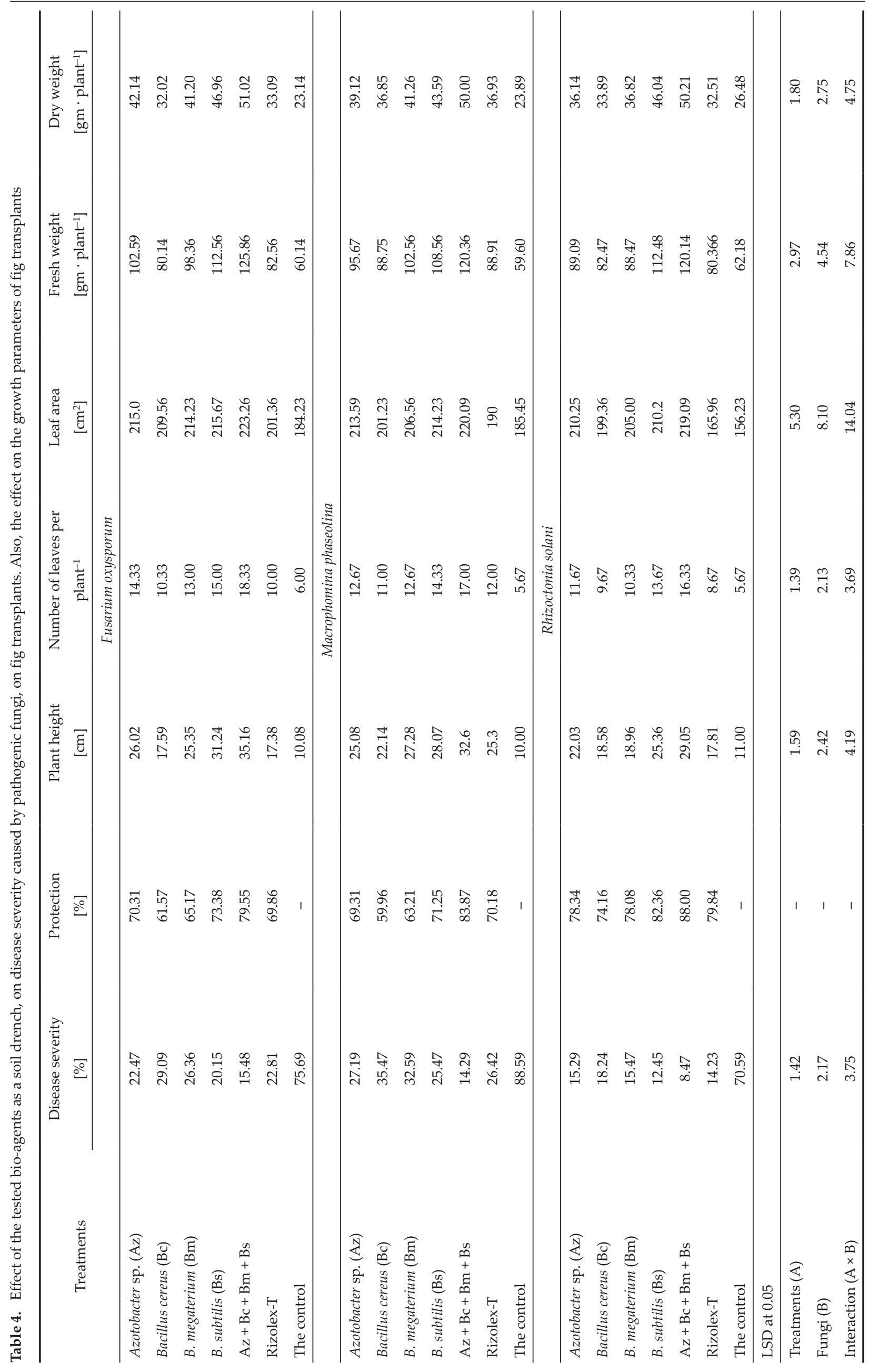




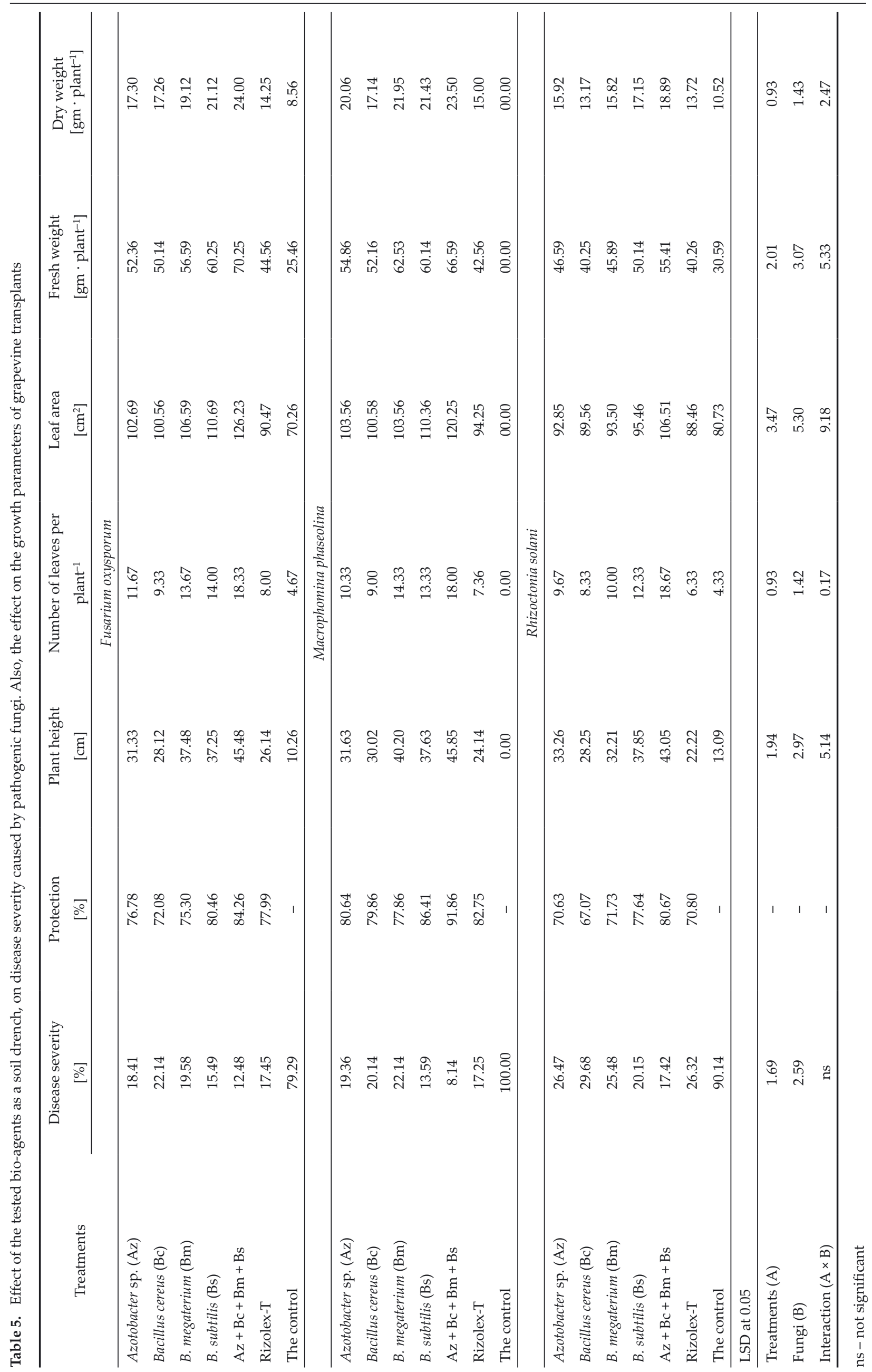




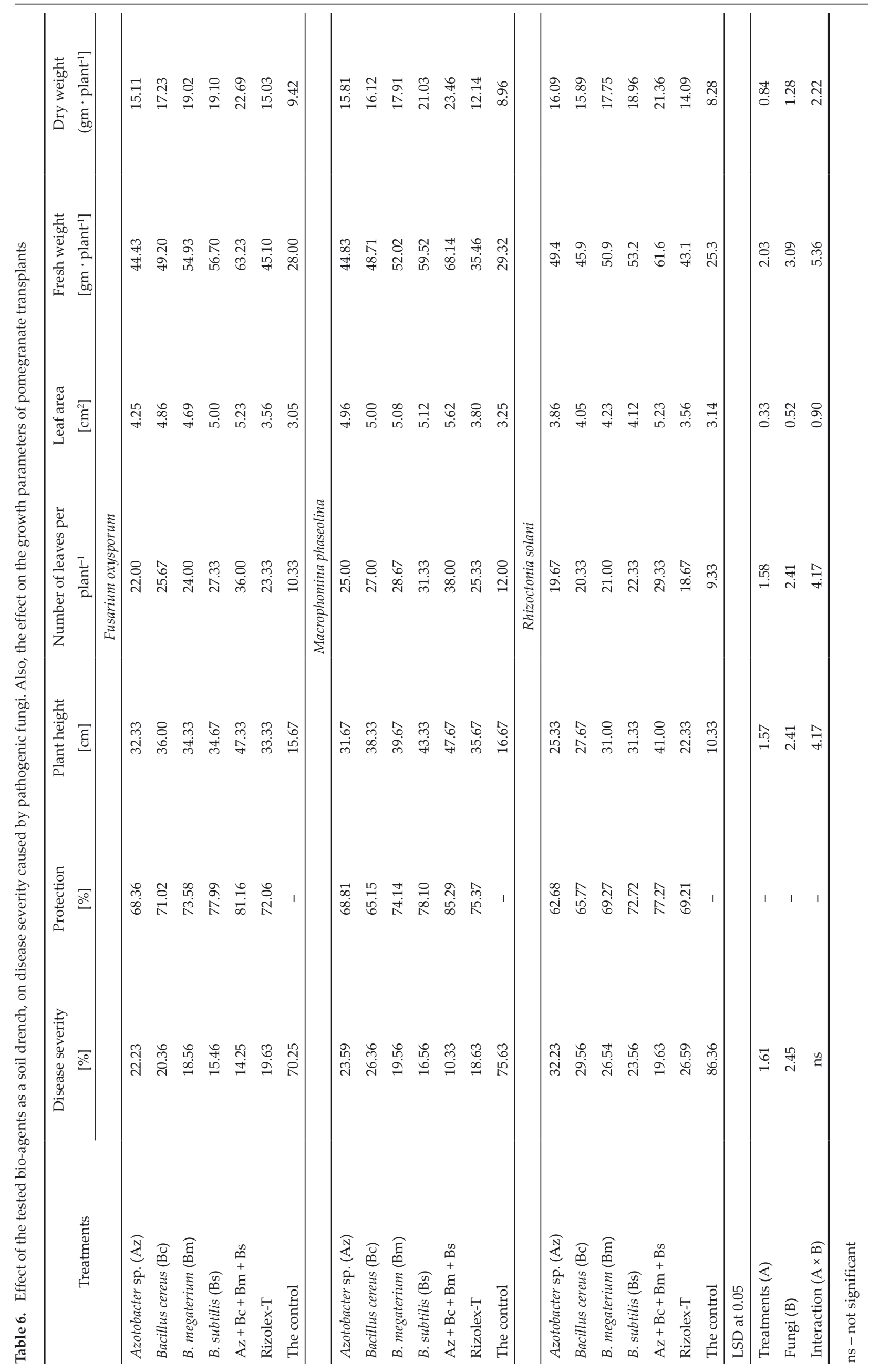




\section{Discussion}

Fig, grapevine, and pomegranate transplants are subject to attack by several soil-borne pathogens, causing severe losses in nurseries and new orchards in the governorate of New Valley, Egypt. The survey was done on the root rot and wilt disease complex in different locations of the governorate of New Valley. The survey indicated that root rot and wilt disease complex is the most important fungal diseases, since it causes major problems on transplants and young trees. The disease incidence and severity differed at the five inspected locations. The high values of disease occurrence and severity may be attributed to the warm, dry conditions in these districts as well as to long-term cultivation of the transplants in the same soils without using correct, strict sanitation methods and preventive therapeutic control measures. The highest means of disease incidence and severity were recorded on grapevine transplants followed by fig transplants. Pomegranate transplants revealed the lowest means. Such results are in agreement with those reported by Walker (1992), Krol (2006), Ziedan and El-Mohamedy (2008), Kishore and Bhardwaj (2011), and Ziedan et al. (2011).

The pathogenicity tests proved that all isolated fungi from rotted root and/or wilted samples of transplants and young trees were pathogenic to fig, grapevine, and pomegranate transplants. The most destructive, though, were F. oxysporum, R. solani, and M. phaseolina. Symptoms of root rot and wilt disease of fig, grapevine, and pomegranate transplants were previously reported by Walker (1992), Omer et al. (1999), Krol (2006), Ziedan and El-Mohamedy (2008), Kishore and Bhardwaj (2011), and Ziedan et al. (2011).

Efficiency of the tested bio-agents for controlling root rot and wilt diseases and for improving vegetative growth parameters, was varied. All the tested bio-agents significantly reduced disease incidence and severity. In this respect, the mix of Azotobacter sp., B. cereus, B. megaterium, $B$. subtilis was more effective than when each was used individually. On the other hand, all treatments significantly increased plant height, number of leaves on the plant, leaf area, and fresh and dry weights when compared with the control treatments. The tested bio-agents have been applied successfully in many ways in plant production as a plant growth stimulant and as a soil conditioner. This positive action of the tested bio-agents: can be of help in the solubilisation of mineral phosphates and other nutrients, can enhance resistance to stress, can stabilize soil aggregates, can improve soil structure and organic matter content, and can retain more soil organic nitrogen and other nutrients in the plant soil system. Bacillus have also been known to produce compounds which promote plant growth directly or indirectly. This refers to such compounds as hydrogen cyanide, siderophores, indole acetic acid, solubilize phosphorus, and antifungal compounds. Bacillus play a role in enhancing natural resistance against plant diseases and pests, stimulating plant growth and effective fertilizers, by increasing cell division. Bacillus optimize the uptake of nutrients and water as well stimulate soil microorganisms, so Bacillus plays a role in reducing root rot and wilt diseases (Kloepper et al. 2004; Dakhly et al. 2007; El-Mohamedy and Ahmad 2009; Baset et al. 2010; Osman and Abd El-Rhman 2010; Abdel-Monaim et al. 2012; Islam et al. 2012; Shobha and Kumudin 2012; AbdelMonaim 2013).

In conclusion, the results of the present study suggest that a soil drench with bio-agents can be used as a safe control measure of disease, in fig, grapevine, and pomegranate transplants, and as a stimulant of vegetative growth parameters.

\section{References}

Abdel-Monaim M.F. 2010. Integrated management of dampingoff, root and/or stem rot diseases of chickpea with sowing date, host resistance and bioagents. Egyptian Journal of Phytopathology 38: 45-61.

Abdel-Monaim M.F. 2013. Improvement of biocontrol of damping-off and root rot/wilt of faba bean by salicylic acid and hydrogen peroxide. Mycobiology 41 (1): 47-55.

Abdel-Monaim M.F., Abdel-Gaid M.A., El-Morsy M.E.A. 2012. Efficacy of rhizobacteria and humic acid for controlling Fusarium wilt disease and improvement of plant growth, quantitative and qualitative parameters in tomato. eSci Journal of Plant Pathology 01: 39-48.

Ahmed F.F., Morsy M.H. 1999. A new method for measuring leaf area in different fruit species. Minia Journal of Agricultural Research and Development 19: 97-105.

Barnett H.L., Hunter B.B. 1986. Illustrated Genera of Imperfect Fungi. 4th ed., Macmillan Publishing Co., New York, USA, 218 pp.

Baset M.M.A., Shamsuddin Z.H., Wahab Z., Marziah M. 2010. Effect of plant growth promoting rhizobacteria inoculation on growth and nitrogen incorporation of tissue-cultured Musa plantlets under nitrogen free hydroponics condition. Australian Journal of Crop Science 4 (2): 85-90.

Dakhly O.F., Ahmed F.F., Rizkk I.A., Uwakim M.K. 2007. Response of young banaty grapevines to bio fertilization with some mutants produced from Azotobacter vinelandii. African Crop Science Conference Proceedings 8: 395-406.

El-Mohamedy R.S.R., Ahmad M.A. 2009. Effect of biofertilizers and humic acid on control of dry root rot disease and improvement yield qualitative of mandarin. Research Journal of Agriculture and Biological Sciences 5: 127-137.

Fokemma N.J. 1973. The role of saprophytic fungi in antagonism against Derchslera sorokiniana on agar plates and on rye leaves with pollen. Physiological Plant Patholology 3 (2): 195-205.

Gomez K.A., Gomez A.A. 1984. Statistical Procedures for Agricultural Research. Wiley, New York, USA, 678 pp.

Islam M.R., Jeong Y.T., Lee Y.S., Song C.H. 2012. Isolation and identification of antifungal compounds from Bacillus subtilis C9 inhibiting the growth of plant pathogenic fungi. Mycobiology 40 (1): 59-66.

Kishore K., Bhardwaj S.S. 2011. Occurrence and incidence of important diseases of pomegranate in Himachal Pradesh. Plant Disease Research 26 (2): 199.

Kloepper J.W., Ryu C.M., Zhang S. 2004. Induced systemic resistance and promotion of plant growth by Bacillus spp. Phytopathology 94 (11): 1259-1266.

Krol E. 2006. Fungi inhabiting decaying grapevine cuttings. Journal of Plant Protection Research 46 (4): 353-358. 
Landa B.B., Navas-Cortes J.A., Jimenez.-Diaz R.M. 2004. Influence of temperature on plant-rhizobacteria interactions related to biocontrol potential for suppression of Fusarium wilt of chickpea. Plant Pathology 53 (3): 341-352.

Liu L., Kloepper J.W., Tuzun S. 1995. Introduction of systemic resistance in cucumber against Fusarium wilt by plant growth-promoting rhizobacteria. Phytopathology 85: 695698.

MSTAT-C 1991. A Software Program for the Design, Management and Analysis of Agronomic Research Experiments. Michigan State University 400.

Omer A.D., Granett J., Wakeman R.J. 1999. Pathogenicity of Fusarium oxysporum on different vitis rootstocks. Journal of Phytopathology 147 (7-8): 433-436.

Osman S.M., Abd El-Rhman I.E. 2010. Effect of organic bio N-fertilization on growth, productivity of fig tree (Ficus carica, L.). Research Journal of Agriculture and Biological Sciences 6 (3): 319-328
Shobha G., Kumudin B.S. 2012. Antagonistic effect of the newly isolated PGPR Bacillus spp. on Fusarium oxysporum. International Journal of Applied Science and Engineering Research 1 (3): 463-474.

Sneh B., Burpee L., Ogoshi A. 1991. Identification of Rhizoctonia Species. APS Press, St. Paul, MN, USA, 133 pp.

Walker G.E. 1992. Root rot of grapevine rootlings in South Australia caused by Rhizoctonia solani. Australasian Plant Pathology 21 (2): 58-60.

Ziedan E.H., Embaby E.M., Farrag E.S. 2011. First record of Fusarium vascular wilt on grapevine in Egypt. Archives of Phytopathology and Plant Protection 44 (17): 1719-1727.

Ziedan E.H.E., El-Mohamedy R.S.R. 2008. Applications of Pseudomonas fluorescens for controlling root rot disease of grapevine. Research Journal of Agriculture and Biological Sciences 4 (5): 346-353. 